\title{
Engaging patients in research using photovoice methodology
}

\author{
Candace I.J. Nykiforuk PhD
}

Cite as: CMAJ 2021 July 12;193:E1050-1. doi: 10.1503/cmaj.210963

See related article at www.cmaj.ca/lookup/doi/10.1503/cmaj.202537

A related study by Campbell and colleagues deftly illustrates how people with lived or living experience of a health concern are in the best position to reveal and evocatively convey the nuanced, circumstantial and structural conditions that shape their health. ${ }^{1}$ These conditions and circumstances may remain otherwise invisible to researchers, practitioners and policy-makers, ultimately undermining health equity, as well as intervention efficacy and effectiveness. Photovoice, the methodology used in the related study, is a participatory, visual-narrative methodology that can powerfully centre the participant voice and perspective in research. A blend of photography and narrative, it has been described as an accessible participatory method through which to engage patients or a community across a wide breadth of health research. ${ }^{2}$ When done well, photovoice methods can be used to cocreate research; patients and academics or clinicians, each drawing from their respective knowledge of a health issue, work together to generate a question, collect data and elucidate meaning from the data to shape action. It has the potential to enrich health research as an avenue for patient coresearchers to share their wisdom and experiences through powerful imagery and story.

Patient engagement in health research has grown in response to demands that research be conducted with, not on, patients to ensure the work is contextually, morally and ethically grounded. ${ }^{3}$ Ideally, patient engagement should lead to the coproduction of research findings that increase the effectiveness of knowledge translation and implementation efforts. For research participants, taking photos can be more meaningful than completing a survey and less intimidating than being asked to participate in an interview or focus group.

Photovoice is a qualitative method characterized by critical engagement and action. Participants are actively engaged to take photographs about the issue under study, one that is important to them or their community, and then to share and discuss their selected key photos, often in a group discussion. Afterward, the resulting photographs and narratives are used to mobilize the research findings to affect policy, practice or community change with policy-makers. ${ }^{4}$ Photovoice methodology offers people some autonomy in the research process; participants choose

\section{KEY POINTS}

- Photovoice is a participatory research methodology that uses photography and narrative to prioritize the lived experiences and perspectives of patients or community members.

- The use of photovoice can enhance patient-engaged research with vulnerable populations, about delicate topics or concerned with promoting health equity.

- When used improperly, participatory methods can be tokenistic, worsen power imbalances and perpetuate inequities experienced by patients.

- Participatory research methods offer a means to address complex health questions that implicate nonmedical determinants of health, sociopolitical structures and dynamic health systems in a collaborative way.

what to photograph (and why), how and when the image is captured, and what is said about the meaning of the image when it is shared with others. They have the opportunity to steward their knowledge through the research process and dissemination, rather than consign it to the researcher to use for study purposes. The use of photovoice can be particularly valuable for research with nonverbal communicators or vulnerable populations, and for research about delicate topics or concerned with promoting health equity through the conduct of the study. ${ }^{5}$

Participants can use photography to express insights or experiences that may be difficult or uncomfortable for them to share in words alone. When they do speak about their photos, participants can explain why they chose to take the photo and how the images are meaningful or important to them, relative to the issue being studied. In this way, researchers are invited to more deeply understand the issue from the participant's perspective and to gain insight on the lived experience of an illness, on their ability to access care, on their interactions with the health care system, or the health and structural inequities underlying those experiences. Researchers see what the participants see, and hear about those sights in the participants' own words. During group discussions, researchers can also witness how each participant's experiences either resonate with or are 
distinct from others in the conversation. Assumptions that are taken for granted can be explored and challenged.

From an implementation science perspective, which aims to reveal what works for whom under what conditions, patient engagement through photovoice can be powerful for revealing the complexities of people's own health and relationships with the health system, and for influencing practice or policy interventions to address targeted health and health system needs. Patient engagement in a photovoice study should transcend engaging people as data sources to welcoming people as coresearchers who help to shape the investigation, contribute knowledge and collaboratively analyze data to produce new insights that will be acted upon by decision-makers.

As with other participatory research approaches, photovoice methodology embodies the principles of social justice and action research to prioritize and respect all partipants' knowledge contributions and desires for community change. Through participatory research, patients and community members are positioned to share their wisdom, contextualized by experience and perspective, as equal contributors to those offering scientific or clinical expertise. As such, they are considered experts alongside academic- or clinician-researchers and, through their involvement in the research, become agents of change in their communities. ${ }^{6}$

In spite of this powerful and reciprocal intent, the value of photovoice and other participatory methods remains, at best, overshadowed by more conventional health research methodologies. At worst, participatory methods can be partially or superficially used, tokenizing patient or community engagement in research. Photovoice methodology itself has been the subject of weighty limitations and ethical concerns, including prioritization of research aims over community action, failure to include community members beyond data collection, data ownership resting with the researcher(s), misrepresentation of research collaborations as effective avenues of policy influence or change, perpetuation of empowerment rhetoric, and breaking trust among coresearchers. ${ }^{5}$ Further, although "a picture may be worth a thousand words," dissemination of photovoice research in the academy is dominated by written culture, often relegating a minimal number of images produced by participants to results sections or supplementary data (decisions typically made by the academic researcher to comply with journal requirements, and not by the participant coresearcher). These limitations perpetuate imbalanced power relations, contradicting the Freirean ${ }^{7}$ underpinnings of photovoice research, and require critical evaluations of power throughout the process.

Substantively addressing these concerns will be essential if we are to make any sustainable gains in equity, diversity and inclusion in the conduct of health research, as recommended by Canadian federal funding agencies. ${ }^{8}$ Participatory research methods, such as photovoice, offer a means to engage patients and their communities in collaboratively addressing complex health questions that implicate nonmedical determinants of health, sociopolitical structures and dynamic health systems. These methods must be employed rigorously and with critical reflection, inviting methodological innovation and improvement to remediate the underrealized value of patient participatory research.

\section{References}

1. Campbell R, Larsen M, DiGiandomenico A, et al. The challenges of managing diabetes while homeless: a qualitative study using photovoice methodology. CMAJ 2021;193:E1034-41.

2. Nykiforuk CIJ, Vallianatos H. Reflection/commentary on a past article: "photovoice as a method for revealing community perceptions of the built and social environment. Int J Qual Methods 2018;Aug. 28. doi: 10.1177/1609406918788236.

3. Bélisle-Pipon J, Rouleau G, Birko S. Early-career researchers' views on ethical dimensions of patient engagement in research. BMC Med Ethics 2018;19:21. doi: 10.1186/s12910-018-0260-y.

4. Wang C, Burris M. Photovoice: concept, methodology, and use for participatory needs assessment. Health Educ Behav 1997;24:369-87.

5. Golden T. Reframing photovoice: building on the method to develop more equitable and responsive research practices. Qual Health Res 2020;30:960-72.

6. Cargo M, Mercer SL. The value and challenges of participatory research: strengthening its practice. Annu Rev Public Health 2008;29:325-50.

7. Freire P. Pedagogy of the oppressed. New York: Routledge; 2013:131-9.

8. Tri-Agency equity, diversity and inclusion action plan for 2018-2025. Ottawa: Government of Canada; modified 2021 Apr. 14. Available: https:// www.nserc-crsng.gc.ca/NSERC-CRSNG/EDI-EDI/Action-Plan_Plan-dAction_ eng.asp (accessed 2021 May 7).

\section{Competing interests: None declared.}

This article was solicited and has not been peer reviewed.

Affiliation: School of Public Health, University of Alberta, Edmonton, Alta.

Content licence: This is an Open Access article distributed in accordance with the terms of the Creative Commons Attribution (CC BY-NC-ND 4.0) licence, which permits use, distribution and reproduction in any medium, provided that the original publication is properly cited, the use is noncommercial (i.e., research or educational use), and no modifications or adaptations are made. See: https://creativecommons.org/licenses/ by-nc-nd/4.0/

Correspondence to: Candace Nykiforuk, candace.nykiforuk@ualberta.ca 